\title{
Estádio de Desenvolvimento e Estresse Hídrico e AS Potencialidades Alelopáticas do Capim-Marandu ${ }^{1}$
}

\author{
Development Stages and Water Stress on the Allelopathic Potential of Marandu Grass
}

\author{
SOUZA FILHO, A.P.S. ${ }^{2}$, ALVES, S.M. ${ }^{3}$ e DUTRA, S. ${ }^{4}$
}

\begin{abstract}
RESUMO - Extratos aquosos da parte aérea da Brachiaria brizantha cv. Marandu, na concentração de 5\%, foram preparados com o objetivo de estudar as prováveis diferenças nas potencialidades alelopáticas desta gramínea em função do estádio de desenvolvimento das plantas e do estresse hídrico (6 e 12 dias sem água). Como plantas receptoras utilizaram-se: Stylosanthes guianensis cv. Mineirão e cv. Bandeirante, Pueraria phaseoloides, Senna obtusifolia, Senna occidentalis, Mimosa pudica, Stachytarpheta cayenennsis e Urena lobata. Os bioensaios foram desenvolvidos em condições de $25{ }^{\circ} \mathrm{C}$ de temperatura e fotoperíodo de 12 horas de luz. Os resultados obtidos mostraram que a germinação foi reduzida em maior magnitude pelos extratos aquosos preparados a partir de material (folhas e colmos) colhido durante a fase vegetativa do capim-marandu, indicando maior concentração de compostos solúveis em água, nesta fase do desenvolvimento da planta, em relação à fase reprodutiva. A imposição do estresse hídrico nas intensidades de 6 e 12 dias, tanto na fase vegetativa como na fase reprodutiva, não promoveu interferências nas potencialidades alelopáticas do capim-marandu.
\end{abstract}

Palavras-chave: fase vegetativa, fase reprodutiva, germinação, aleloquímico, alelopatia.

ABSTRACT - Aqueous extracts from above ground tissue of Brachiaria brizanta cv. Marandu at a concentration of 5\%, were prepared to study the possible differences in the allelopathic potential of this species, influenced by its development stage and water stress (six and twelve days without irrigation). Stylosanthes guianensis $c v$. Mineirão and $c v$. Bandeirante, Pueraria phaseoloides, Senna obtusifolia, Senna occidentalis, Mimosa pudica, Stachytarpheta cayenennsis and Urena lobata were used as the receiving species. The bioassays were developed under $25^{\circ} \mathrm{C}$ and a 12-hour photoperiod. Germination was reduced in a greater proportion by aqueous extracts prepared from leaves and stems collected during the vegetative stage of Marandu grass, indicating a greater concentration of soluble compounds in water during this stage than during the reproductive stage. Water stress had no effect on the allelophatic potential of Marandu grass.

Key words: vegetative stage, reproductive stage, germination, allelochemical, allelophaty.

\section{INTRODUÇÃO}

As plantas superiores produzem e estocam grande número de produtos do metabolismo secundário, os quais são posteriormente liberados para o meio ambiente de diferentes formas, como volatilização, exsudação radicular, lixiviação - remoção de substâncias químicas das plantas vivas ou mortas pelas águas das chuvas e do orvalho -, e também através da decomposição dos resíduos de plantas (Whittaker \& Feeny, 1971; Einhellig, 1986; Rice, 1987). Por

Recebido para publicação em 8/10/2001 e na forma revisada em 15/3/2002.

Eng.-Agr., Dr., Embrapa Amazônia Oriental, Trav. Dr. Enéas Pinheiro, S/N, 66095-100 Belém-Pará, <apedro@cpatu.embrapa.br>; ${ }^{3}$ Quím., M.S., Embrapa Amazônia Oriental, <sergio@cpatu.embrapa.br>; ${ }^{4}$ Eng.-Agr., M.S., Embrapa Amazônia Oriental, <sdutra@cpatu.embrapa.br>. 
muitos anos, os biólogos e químicos tentam responder por que as plantas investem tanta energia e cuidados na formação desses produtos. Algumas vezes acreditou-se que esses compostos eram produtos perdidos ou substâncias inúteis. No entanto, mais recentemente, reconhece-se que esses metabólitos secundários desempenham importante papel ecológico das plantas e são cruciais para a sua sobrevivência e aptidão (Harborne, 1986; Wink, 1988). As principais funções que esses compostos desempenham parecem estar associadas à defesa da planta contra agentes como vírus, bactérias e fungos, nematóides, insetos e, também, contra a competição por plantas (Waller, 1989; Wink \& Twardowski, 1992).

Praticamente todas as plantas têm potencial para produzir e estocar grande número de metabólitos secundários (alcalóides, óleos essenciais, compostos fenólicos, esteróides, terpenóides, flavonóides, cumarinas), os quais podem se originar de diferentes rotas biossintéticas e apresentar variações na sua concentração e localização, de acordo com a espécie (Bansal \& Bhan, 1993). Em diferentes bioensaios, esses compostos já foram encontrados nas folhas, nos caules, nas flores, nos rizomas, nas raizes e nos frutos e sementes de diferentes espécies de plantas. Especificamente para a graminea forrageira Brachiaria brizantha cv. Marandu (capim-marandu), as evidências indicam atividade alelopática nessa espécie, sendo a parte aérea a principal fonte de substâncias potencialmente alelopáticas, solúveis em água (Carvalho, 1993; Souza Filho, 1995).

As principais rotas biossintéticas desses compostos são a via do acetato e/ou do ácido chiquímico (Einhellig, 1995). No entanto, muito pouco se sabe a respeito dos fatores que podem controlar a produção desses compostos e de como essa produção se comporta em função do estádio de desenvolvimento da planta. Com relação aos efeitos de estresse sobre a produção de substâncias alelopáticas, as informações disponíveis, embora se reconheça que não se referem às plantas forrageiras, mostram que vários compostos alelopáticos produzidos pelas plantas são regulados por fatores ambientais como temperatura, umidade do solo, intensidade, qualidade e duração de luz, disponibilidade de nutrientes, além de outros fatores, como a aplicação de herbicidas (Chou \& Kuo, 1986;
Chou, 1986; Cheng, 1992). Entretanto, enquanto a concentração de alguns aleloquímicos aumenta na planta sob estresse, outros podem não repetir esse mesmo comportamento (Wender, 1970).

O objetivo da presente pesquisa foi determinar as variações nas potencialidades alelopáticas da gramínea forrageira Brachiaria brizantha cv. Marandu em função do desenvolvimento vegetativo e do estresse hídrico.

\section{MATERIAL E MÉTODOS}

\section{Experimento I - Efeito do estádio de desenvolvimento da planta}

A gramínea Brachiaria brizantha cv. Marandu (capim-marandu) foi cultivada em um Latossolo Amarelo textura média, ácido e de baixa fertilidade natural, no Campo Experimental da Embrapa Amazônia Oriental, localizado em Belém-PA. O plantio foi realizado no início do período chuvoso (fevereiro de 1996),

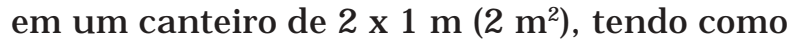
adubação de estabelecimento $100 \mathrm{~kg}$ de $\mathrm{P}_{2} \mathrm{O}_{5}$ (superfosfato simples), $100 \mathrm{~kg}$ de $\mathrm{N}$ (uréia) e $60 \mathrm{~kg}$ de $\mathrm{K}_{2} \mathrm{O} \mathrm{ha}^{-1}$ (cloreto de potássio). O fósforo foi aplicado de uma única vez, no plantio, enquanto o nitrogênio e o potássio foram aplicados em duas etapas, metade no plantio e o restante 30 dias após a emergência das plântulas.

A coleta de material (parte aérea) para preparo dos extratos aquosos foi realizada considerando-se duas fases distintas do desenvolvimento das plantas: vegetativa e reprodutiva (início da floração). A coleta correspondente à fase vegetativa foi realizada três meses após a emergência das plântulas, enquanto a da fase reprodutiva foi realizada no início da floração, quando 30 plantas apresentavam-se em floração. Como as plantas não floresceram até o mês de junho, foi realizado no início de mês de julho um corte de uniformização da pastagem. Esse procedimento permitiu a uniformização das idades de coleta, visto que as plantas floresceram no mês de outubro; portanto, também aos três meses de idade. O corte foi realizado a cinco centímetros do solo, sendo a amostra da fase vegetativa composta de folhas e colmos e a da fase reprodutiva, de folhas, colmos e inflorescências. 
Como parâmetro de comparação (testemunha) utilizou-se uma solução aquosa com potencial osmótico ajustado ao potencial osmótico do extrato aquoso $(0,12 \mathrm{MPa})$. Essa solução foi obtida com polietilenoglicol-6000 (PEG-6000).

\section{Experimento II - Efeito do estresse hídrico}

O capim-marandu foi cultivado em caixas com capacidade para 100 litros, contendo solo peneirado, classificado como Latossolo Amarelo textura média. A adubação de estabelecimento, bem como a aplicação dos fertilizantes, foram as mesmas utilizadas no trabalho anteriormente descrito. O trabalho foi realizado em casa de vegetação com as paredes laterais abertas, sem controle de temperatura, no Campo Experimental da Embrapa Amazônia Oriental, em Belém-PA.

Foram estabelecidos dois níveis de estresse hídrico no capim-marandu: 6 e 12 dias sem que as plantas recebessem água. Esses níveis foram impostos à gramínea em duas fases distintas do desenvolvimento das plantas: vegetativa e reprodutiva (início da floração). Considerou-se como fase reprodutiva o momento em que cada caixa apresentava no mínimo 20 plantas florescendo e, como fase vegetativa, quando a planta estava com três meses de idade. A uniformização das idades de coleta, nas duas fases de desenvolvimento das plantas, foi realizada à semelhança do primeiro experimento. Antecedendo esse período, as plantas vinham recebendo água diariamente. Para efeito de comparação (tratamento considerado testemunha), foram mantidas duas caixas com irrigação, uma correspondente à fase vegetativa e outra à fase reprodutiva, que foram cortadas na mesma ocasião das parcelas que receberam o estresse hídrico.

As plantas foram cortadas a cinco centímetros do solo, nas respectivas épocas estabelecidas. A amostra correspondente à fase vegetativa era composta de folhas e colmos, e a da reprodutiva, de folhas, colmos e inflorescências.

\section{Preparo dos extratos aquosos}

O material colhido foi seco em estufa com circulação de ar forçada, por 72 horas, a uma temperatura de $39{ }^{\circ} \mathrm{C}$ e triturado em moinho de faca tipo Willey. Para ambos os experimentos, os extratos aquosos foram preparados na concentração de 5\%, que é aquela mais comumente utilizada em bioensaios usando extratos de plantas (Stowe, 1979). Os extratos foram deixados em repouso por seis horas, filtrados a vácuo e mantidos em temperatura ambiente até o momento de serem utilizados.

\section{Bioensaios de germinação desenvolvidos}

O potencial alelopático dos extratos aquosos foi avaliado através de seus efeitos sobre a germinação das sementes das seguintes espécies receptoras: Stylosanthes guianensis cv. Mineirão (mineirão) e cv. Bandeirante (bandeirante), Pueraria phaseoloides (puerária), Senna obtusifolia (mata-pasto), Senna occidentalis (fedegoso), Mimosa pudica (malícia), Urena lobata (malva) e Stachytarpherta cayennensis (rinchão), sendo esta última utilizada apenas no experimento I.

Antecedendo a realização de cada experimento, foram desenvolvidos testes para avaliar o potencial de germinação das sementes das espécies receptoras. Esses testes foram conduzidos nas mesmas condições empregadas nos bioensaios. Os resultados mostraram que as sementes não apresentavam problemas de germinação. As sementes das espécies de plantas daninhas e da puerária foram coletadas em áreas de fazendas particulares, localizadas no município de Castanhal-PA, enquanto as sementes de Mineirão e de Bandeirante foram adquiridas na Embrapa Gado de Corte, Campo Grande-MS. As sementes coletadas passaram por um processo de limpeza e expurgo e foram tratadas com vistas à quebra da dormência (Souza Filho et al., 1998; Souza Filho et al., 1999).

A germinação foi monitorada em períodos de 15 dias, com contagens diárias e eliminação das sementes germinadas. Os bioensaios foram desenvolvidos em condições de $25^{\circ} \mathrm{C}$ de temperatura e fotoperíodo de 12 horas de luz. Foram consideradas sementes germinadas as que apresentavam extensão radicular igual ou superior a 2 mm (Juntila, 1976; Duran \& Tortosa, 1985).

Planta Daninha, Viçosa-MG, v.20, n.1, p.25-31, 2002 
Cada caixa tipo gerbox transparente, de 11 x $11 \mathrm{~cm}$, forrada com duas folhas de papel filtro autoclavadas a $120{ }^{\circ} \mathrm{C}$, recebeu 50 sementes. Para cada gerbox, adicionavam-se $8 \mathrm{ml}$ do extrato aquoso-teste, com igual volume para os tratamentos testemunha. O extrato foi adicionado apenas no início dos bioensaios, sendo, a partir de então, adicionada apenas água destilada, sempre que necessário.

\section{Análise estatística}

O delineamento experimental utilizado para os dois bioensaios foi o inteiramente casualizado, com três repetições, sendo os tratamentos arranjados em esquema hierárquico com dois fatores. Os dados foram submetidos à análise de variância pelo teste $\mathrm{F}$ e as médias comparadas pelo teste de Tukey em nivel de erro de 0,05. As análises estatísticas foram realizadas utilizando-se o SAS (SAS, 1989), de acordo com os seguintes modelos matemáticos:

\section{Para o experimento I}

$$
Y i j k=m+A i+B j(i)+E i j k
$$

em que Yijk = percentagem de germinação das sementes; $\mathrm{Ai}=$ espécie receptora; $\mathrm{m}=$ média geral; $\mathrm{Bj}(\mathrm{i})=$ efeito da fase de desenvolvimento dentro de espécie; e Eijk = erro experimental.

\section{Para o experimento II}

$$
Y i j k=m+A i+B j(i)+E i j k
$$

em que Yijk = percentagem de germinação das sementes da espécie receptora; $\mathrm{m}$ = média geral; $\mathrm{Ai}=$ fase do desenvolvimento da planta; $\mathrm{Bj}(\mathrm{i})=$ nível de estresse hídrico dentro da fase de desenvolvimento j; e Eijk = erro experimental.

\section{RESULTADOS E DISCUSSÃO}

\section{Experimento I - Efeito do estádio de desenvolvimento da planta}

A germinação das sementes das espécies receptoras variou estatisticamente $(p<0,05)$ entre os tratamentos experimentais. Quando na presença do extrato aquoso preparado a partir de material (parte aérea) colhido durante a fase vegetativa do capim-marandu, a germinação das sementes foi sempre inferior $(p<0,05)$ aos valores obtidos para os tratamentos testemunha e extrato aquoso de material colhido durante a fase reprodutiva da gramínea (Tabela 1).

Tabela 1 - Efeitos de extratos aquosos da parte aérea de capim-marandu, colhida em diferentes fases de desenvolvimento, sobre a germinação (\%) de sementes

\begin{tabular}{|l|c|c|c|}
\hline \multirow{2}{*}{$\begin{array}{c}\text { Espécie } \\
\text { receptora }\end{array}$} & \multicolumn{3}{|c|}{ Fase de desenvolvimento } \\
\cline { 2 - 4 } & Testemunha & Vegetativa & Reprodutiva \\
\hline Mineirão & $78,33 \mathrm{a}$ & $64,00 \mathrm{~b}$ & $77,33 \mathrm{a}$ \\
Bandeirante & $70,00 \mathrm{a}$ & $59,33 \mathrm{~b}$ & $69,00 \mathrm{a}$ \\
Puerária & $90,00 \mathrm{a}$ & $78,67 \mathrm{~b}$ & $87,00 \mathrm{a}$ \\
Malva & $88,00 \mathrm{a}$ & $66,00 \mathrm{c}$ & $72,00 \mathrm{~b}$ \\
Malícia & $82,00 \mathrm{a}$ & $17,33 \mathrm{c}$ & $52,00 \mathrm{~b}$ \\
Rinchão & $67,33 \mathrm{a}$ & $24,00 \mathrm{c}$ & $40,67 \mathrm{~b}$ \\
Fedegoso & $88,67 \mathrm{a}$ & $50,00 \mathrm{c}$ & $69,67 \mathrm{~b}$ \\
Mata-pasto & $92,00 \mathrm{a}$ & $63,33 \mathrm{~b}$ & $91,00 \mathrm{a}$ \\
\hline
\end{tabular}

Médias seguidas de letras iguais na linha não diferem entre si pelo teste de Tukey $(\mathrm{P}>0,05)$.

Os dados disponíveis na literatura mostram que os efeitos alelopáticos dependem, entre outros fatores, da concentração dos aleloquímicos, e quanto mais elevada for a concentração do aleloquímico, maior a sua ação deletéria sobre os processos metabólitos da planta-alvo (Rice, 1984; Smith, 1989; White et al., 1989; Williamson et al., 1992). Os resultados deste trabalho são um indicativo de que, durante a fase vegetativa, o capim-marandu apresenta maior concentração de substâncias potencialmente alelopáticas inibitórias, solúveis em água, do que na fase reprodutiva.

Os dados da Tabela 1 mostram, ainda, que a germinação das sementes das espécies receptoras mineirão, bandeirante, puerária e mata-pasto não diferiu estatisticamente ( $>0,05)$ entre os tratamentos testemunha e extrato aquoso correspondente à fase reprodutiva do capim-marandu. Aparentemente, durante esta fase de desenvolvimento, as substâncias potencialmente alelopáticas, solúveis em água, presentes no capim-marandu estão em niveis inferiores àqueles requeridos para promover inibições na germinação das sementes dessas espécies. Esses aspectos são importantes e devem ser considerados em estudos de bioensaios de alelopatia. Isso porque podem gerar interpretações errôneas na 
avaliação das potencialidades alelopáticas de uma espécie forrageira, subestimando-as numa espécie doadora, como também sugerindo a ausência de efeitos potencialmente alelopáticos em espécie onde esta característica está presente.

Muito pouco se sabe a respeito da produção de substâncias com potencialidades alelopáticas em plantas forrageiras, em especial sobre as prováveis variações na intensidade de produção de aleloquímicos durante o ciclo da planta. Wardle (1987) menciona que as plantas de pastagens são provavelmente alelopáticas apenas em certos estádios de seu ciclo de vida. Essa informação não foi observada em toda a sua extensão no presente trabalho. No entanto, os dados da Tabela 1 mostram que as potencialidades alelopáticas não são uniformes durante o ciclo das plantas e podem variar em intensidade, em função da fase de desenvolvimento da planta ou, talvez, com a idade de crescimento desta.

É provável que as diferenças observadas nas potencialidades alelopáticas entre as duas fases de desenvolvimento do capim-marandu (Tabela 1) estejam associadas à liberação de substâncias alelopáticas - solúveis em água, presentes na parte aérea do capim-marandu para o meio ambiente, no início da fase reprodutiva, pelas mais diferentes formas, como volatilização, exsudação radicular e lixiviação pela água da chuva (Whittaker \& Feeny, 1971; Einhellig, 1986; Rice, 1987). Essa liberação poderia ser atribuída à necessidade de a planta garantir a perpetuação da espécie, estabelecendo condições ambientais menos estressantes à germinação das sementes e ao desenvolvimento das plântulas.

\section{Experimento II - Efeito do estresse hídrico}

A análise de variância para os efeitos do estresse hídrico foi realizada tendo por base os fatores fase de desenvolvimento das plantas e niveis de estresse (fase). Os resultados obtidos para os efeitos de fase foram significativos para todas as espécies receptoras (Tabela 2). A comparação de médias apresentada na Tabela 3 mostra diferenças estatísticas nas potencialidades alelopáticas do capim-marandu entre as duas fases de desenvolvimento das plantas, sendo os efeitos inibitórios promovidos pelo extrato aquoso preparado a partir do material (folhas e colmos) colhido durante a fase vegetativa superiores $(\mathrm{P}<0,05)$ aos da fase reprodutiva. Esse resultado repete aquele obtido no primeiro experimento, dispensando maiores considerações.

Tabela 2 - Quadrados médios (QM) obtidos da análise de variância para as percentagens de germinação entre fases de desenvolvimento das plantas e níveis de estresse (fase), por espécie receptora

\begin{tabular}{|c|c|c|}
\hline Espécie receptora & Fontes de variação & QM \\
\hline Mineirão & $\begin{array}{l}\text { Fases de desenvolvimento } \\
\text { Níveis de estresse (fase) }\end{array}$ & $\begin{array}{r}684,5^{*} \\
4,2^{\text {ns }}\end{array}$ \\
\hline Bandeirante & $\begin{array}{l}\text { Fases de desenvolvimento } \\
\text { Níveis de estresse (fase) }\end{array}$ & $\begin{array}{r}43,6^{*} \\
2,9^{\text {ns }}\end{array}$ \\
\hline Puerária & $\begin{array}{l}\text { Fases de desenvolvimento } \\
\text { Níveis de estresse (fase) }\end{array}$ & $\begin{array}{r}533,6^{*} \\
3,1^{\mathrm{n}} \\
\end{array}$ \\
\hline Mata-pasto & $\begin{array}{l}\text { Fases de desenvolvimento } \\
\text { Níveis de estresse (fase) }\end{array}$ & $\begin{array}{r}3146,9^{*} \\
4,9^{\text {ns }} \\
\end{array}$ \\
\hline Fedegoso & $\begin{array}{l}\text { Fases de desenvolvimento } \\
\text { Níveis de estresse (fase) }\end{array}$ & $\begin{array}{r}37,6^{*} \\
3,7^{\text {ns }} \\
\end{array}$ \\
\hline Malícia & $\begin{array}{l}\text { Fases de desenvolvimento } \\
\text { Níveis de estresse (fase) }\end{array}$ & $\begin{array}{r}1.780,1^{*} \\
0,9^{\text {ns }}\end{array}$ \\
\hline Malva & $\begin{array}{l}\text { Fases de desenvolvimento } \\
\text { Níveis de estresse (fase) }\end{array}$ & $\begin{array}{r}2.426,7^{*} \\
2,4^{\text {ns }}\end{array}$ \\
\hline
\end{tabular}

* = significativo em nível de erro de 0,05.

${ }^{\text {ns }}=$ não-significativo em nível de erro de 0,05.

Tabela 3 - Análise comparativa para efeito da fase de desenvolvimento do capim-marandu nas potencialidades alelopáticas, em função de diferentes níveis de estresse hídrico. Dados expressos em percentual de germinação

\begin{tabular}{|c|c|c|c|c|}
\hline \multirow{2}{*}{$\begin{array}{l}\text { Espécie } \\
\text { receptora }\end{array}$} & \multirow{2}{*}{$\begin{array}{c}\text { Fase de } \\
\text { desenvolvimento }\end{array}$} & \multicolumn{3}{|c|}{ Nível de estresse (dias) } \\
\hline & & 0 & 6 & 12 \\
\hline \multirow{2}{*}{ Mineirão } & Vegetativa & $64,0 \mathrm{~b}$ & $64,0 b$ & $62,0 \mathrm{~b}$ \\
\hline & Reprodutiva & $78,0 \mathrm{a}$ & $76,0 \mathrm{a}$ & $76,0 \mathrm{a}$ \\
\hline \multirow{2}{*}{ Bandeirante } & Vegetativa & $60,0 \mathrm{~b}$ & $62,0 \mathrm{~b}$ & $61,0 \mathrm{~b}$ \\
\hline & Reprodutiva & $76,0 \mathrm{a}$ & $74,0 \mathrm{a}$ & $74,0 \mathrm{a}$ \\
\hline \multirow{2}{*}{ Puerária } & Vegetativa & $74,0 \mathrm{~b}$ & $73,0 \mathrm{~b}$ & $73,0 \mathrm{~b}$ \\
\hline & Reprodutiva & $86,0 \mathrm{a}$ & $85,0 \mathrm{a}$ & $86,0 \mathrm{a}$ \\
\hline \multirow{2}{*}{ Mata-pasto } & Vegetativa & $63,0 \mathrm{~b}$ & $66,0 \mathrm{~b}$ & $63,0 \mathrm{~b}$ \\
\hline & Reprodutiva & $90,0 \mathrm{a}$ & $88,0 \mathrm{a}$ & $90,0 \mathrm{a}$ \\
\hline \multirow{2}{*}{ Fedegoso } & Vegetativa & $50,0 \mathrm{~b}$ & $48,0 \mathrm{~b}$ & $48,0 \mathrm{~b}$ \\
\hline & Reprodutiva & $69,0 \mathrm{a}$ & $67,0 \mathrm{a}$ & $66,0 \mathrm{a}$ \\
\hline \multirow{2}{*}{ Malícia } & Vegetativa & $17,0 \mathrm{~b}$ & ' $18,0 \mathrm{~b}$ & $18,0 \mathrm{~b}$ \\
\hline & Reprodutiva & $52,0 \mathrm{a}$ & $50,0 \mathrm{a}$ & $51,0 \mathrm{a}$ \\
\hline \multirow{2}{*}{ Malva } & Vegetativa & $68,0 \mathrm{~b}$ & $66,0 \mathrm{~b}$ & $68,0 \mathrm{~b}$ \\
\hline & Reprodutiva & $81,0 \mathrm{a}$ & $80,0 \mathrm{a}$ & $78,0 \mathrm{a}$ \\
\hline
\end{tabular}

Médias seguidas de letras iguais na linha não diferem entre si pelo teste de Tukey $(\mathrm{P}>0,05)$.

Planta Daninha, Viçosa-MG, v.20, n.1, p.25-31, 2002 
Os dados da Tabela 2 mostram, também, que a imposição de 6 e 12 dias de estresse hídrico não promoveu efeitos $(\mathrm{P}>0,05)$ sobre as potencialidades alelopáticas do capim-marandu, tanto quando o estresse foi imposto na fase vegetativa como na fase reprodutiva, em relação ao tratamento testemunha (sem estresse).

Poucas investigações têm sido conduzidas acerca do efeito do déficit de água sobre a quantidade de aleloquímicos presentes na planta, e provavelmente menos ainda foram realizadas para plantas de pastagens. Entretanto, considerando que alelopatia é um agente de competição que trabalha para inibir aquelas plantas que poderiam exercer competição por fatores essenciais à sobrevivência de ambas as plantas, como luz, água, nutrientes e espaço, então poder-se-ia deduzir que mais aleloquímicos poderiam ser produzidos também quando essas fontes estivessem em níveis limitados. Nesse sentido, alguns estudos mostram que plantas estressadas geralmente apresentam maior ação alelopática do que aquelas não-estressadas (Koeppe et al., 1976; Hall et al., 1983). Similarmente, uma variedade de trabalhos mostra que a deficiência de umidade no solo causa aumentos na concentração de fenóis, monoterpenos e ácidos hidroxâmicos (Einhellig, 1987, 1989; Tang et al., 1995).

A ausência de resposta do capim-marandu aos dois níveis de estresse hídrico (6 e 12 dias), quer quando imposto à planta na fase vegetativa quer na fase reprodutiva (Tabela 2), é um indicativo de que essa resposta nem sempre se verifica e de que o fator espécie estudada tem influência no resultado final. Uma das hipóteses a serem consideradas para esse resultado é a de que a Brachiaria brizantha cv. Marandu é uma gramínea forrageira originária da África, de ambiente com precipitações pluviais anuais em torno de $700 \mathrm{~mm}$ e de cerca de oito meses de seca (Ghisi \& Pedreira, 1987), que tem sido utilizada desde a sua introdução no Brasil sem que tenha passado por um processo de melhoramento genético. Dessa maneira, esta graminea forrageira é bem adaptada às condições de déficit hídrico extremo, não respondendo a um estímulo para o qual é, originalmente, adaptada. Assim, níveis de estresse hídrico tão baixos como os usados neste trabalho não promoveriam efeitos sobre as suas potencialidades alelopáticas.
Uma outra hipótese estaria relacionada aos resultados obtidos por Wender (1970), mostram que nem todas as substâncias alelopáticas têm a sua produção aumentada em resposta a um estímulo externo. Embora não se tenha identificado as substâncias alelopáticas presentes no capim-marandu, é provável que estas tenham a mesma natureza daquelas estudadas por Wender (1970), até porque são produzidas por uma planta que tem sua origem em ambientes extremamente estressantes, especialmente com relação ao déficit hídrico.

\section{LITERATURA CITADA}

BANSAL, G. L.; BHAN, V. M. Status of research on allelopathy and future scope of work in Indian. Ind. J. Agric. Sci., v. 63, n. 12, p. 769-776, 1993.

CARVALHO, S. J. C. Caracterização dos efeitos alelopáticos de Brachiaria brizantha cv. Marandu, no estabelecimento das plantas de Stylosanthes guianensis var. Vulgaris e cv. Bandeirante. Viçosa-MG: Universidade Federal de Viçosa, 1993. 72 p. Dissertação (Mestrado em Zootecnia) - Universidade Federal de Viçosa, 1993.

CHENG, H. H. A. A conceptual framework for assissing allelochemicals in the soil enviromental. In: RIZVI, S. J. H.; RIZVI, V. (Eds.) Allelophaty. New York: Chapman \& Hall, 1992. p. 21-29.

CHOU, C. H. The role of allelopathy in subtropical agroecosystems in Taiwan. In: PUTNAM, A R.; TANG, C. S. (Eds.) The science of allelopathy. New York: John Wiley \& Sons, 1986. p. 57-73.

CHOU, C. H.; KUO, Y. L. Allelopathy research of subtropical vegetation inTaiwan. III - Allelopathic exclusion of understory by Leucaena leucocephala (Lam.) de Wit. J. Chem. Ecol., v. 12, n. 6, p. 1431-1444, 1986.

DURAN, J. M.; TORTOSA, M. E. The effect of mechanical and chemical scarification on germination of chalock (Sinapis arvensis L.) seeds. Seed Sci. Technol., v. 13, n. 1, p. 155-163, 1985.

EINHELLIG, F. A. Mechanisms and mode of action of allelochemicals. In: PUTNAM, A. R.; TANG, C. S. (Eds.) The science of allelopathy. New York: John Willey \& Sons, 1986. p. 171-188.

EINHELLIG, F. A. Interaction among allelochemicals and other stress factors of the plant environment. In: WALLER, G. R. Allelochemicals: role in agriculture and forestry. Washington, D.C.: American Chemical Society, 1987. p. 343-357 (ACS Symposium Series, 330). 
EINHELLIG, F. A . Interaction effects of allelochemicals and enviromental stress. In: CHOU, C. H.; WALLER, G. R. Phytochemical ecology: allelochemicals mycotoxins and insect pheromones and allomones. Taipei: Academia Sinica, 1989. p. 101-118. (Academia Sinica Monograph Series, 9).

EINHELLIG, F.A . Plant x plant allelopathy: biosynthesis and machanism of action. In: CONGRESSO BRASILEIRO DE FISIOLOGIA VEGETAL, 5, 1995, Lavras-MG. Anais...Lavras-MG: Sociedade Brasileira de Fisiologia Vegetal, 1995. p. 59-74.

GHISI, O. M. A.; PEDREIRA, J. V. S. Características agronômicas das principais Brachiaria spp. In: ENCONTRO SOBRE CAPINS DO GÊNERO Brachiaria, 1987, Nova Odessa-SP. Anais... Nova Odessa-SP: Instituto de Zootecnia, 1987. p. 19-57.

HALL, A. B.; BLUM, V.; FITES, R. C. Stress modifications of allelopathy of Helianthus annus L. debris on seed germination. Am. J. Bot., v. 69, p. 776-783, 1983.

HARBORNE, F. B. Recent advances in chemical ecology. Nat. Product. Rep., v. 3, p. 323-344, 1986.

JUNTILA, O. Seed and embryo germination in S. vulgaris and $S$. reflexa as effects by temperature during seed development. Physiol. Plant., v. 29, p. 264-268, 1976.

KOEPPE, D. E.; SOUTHWICK, L. M.; BITTEL, J. E. The relationship of tissue chlorogenic acid concentration and leaching of phenolics from samflowers grown under varying phosphorus nutrients conditions. Can. J. Bot., v. 54, p. 593-599, 1976.

RICE, E. L. Allelopathy. 2.ed. New York: Academic Press, 1984. $422 \mathrm{p}$.

RICE, E. L. Allelopathy: an overview. In: WALLER, G. R. Allelochemical, role in agriculture and forestry. Washington, D.C.: American Chemical Society, 1987. p. 7-22. (ACS. Symposium Series, 330).

STATISTICAL ANALYSIS SYSTEM - SAS. User's Guide. Version 6. 4.ed. North Caroline: SAS Institute Inc., 1989. $846 \mathrm{p}$.

SMITH, A. E. The potential allelopathic characteristcs of bitter sneezeweed (Helenium amarum). Weed Sci., v. 37, p. 665-669, 1989.

SOUZA FILHO, A. P. S. Potencialidades alelopáticas envolvendo gramíneas e leguminosas forrageiras e plantas invasoras de pastagens. Jaboticabal: Universidade Estadual Paulista, 1995. 137 p. Tese (Doutorado em Zootecnia) - Universidade Estadual Paulista, 1995.
SOUZA FILHO, A. P. S.; SILVA, M. A. M. M.; DUTRA, S. Quebra de dormência em sementes de Pueraria

phaseoloides (Roxburg) Bentham. Past. Tropic., v. 21, n. 2, p. 29-33, 1999.

SOUZA FILHO, A. P. S.; DUTRA, S.; SILVA, M. A. M. M. Métodos de superação da dormência de sementes de plantas daninhas de pastagens cultivadas da Amazônia. Planta Daninha, v. 16, n. 1, p. 3-11, 1998.

STOWE, L. G. Allelopathy and its influence on the distribution of plants in na Illinois old- field. J. Ecol., v. 67, p. 1065-1085, 1979.

TANG, C. S. et al. Plant stress and allelopathy. In: INDERSIT, K. M. M.; EINHELLIG, F.A. (Eds.) Allelopathy: organisms, processes and applications. Washington, D.C.: American Chemical Society, 1995. p. 142-157. (ACS Symposium Series, 582).

WALLER, G. R. Biochemical frontieries of allelopathy. Biol. Plant., v. 36, n. 6, p. 418-447, 1989.

WARDLE, D. A. Allelopathy in Zealand pasture grassland ecosystem. N. Z. J. Exp. Agric., v. 15, p. 243-255, 1987.

WENDER, S. H. Effects of some enviromental stress factor on certain phenolic compounds in tabacco. Recent Adv. Phytochem., v. 3, p. 1-29, 1970.

WHITE, R. H.; WORSHAM, A. D.; BLUM, V. Allelopathic potential of legume debris and aqueous extracts. Weed Sci., v. 37, p. 674-679, 1989.

WHITTAKER, R. H.; FEENY, P. P. Allelochemies: chemical interction between species. Science, v. 171, p. 757-770, 1971.

WILLIAMSON, G. B.; RICHARDSON, D. R.; FISCHER, N. H. Allelopathic mechanism in fire - prone communities. In: RIZVI, S. J. H.; RIZVI, V. (Eds.) Allelopathy. New York: Chapman \& Hall, 1992. p. 59-75.

WINK, M. Plant breeding: importance of plant secondary metabolites for protection against pathogens and herbovires. Theor. Appl. Genet., v. 75, p. 225-233, 1988.

WINK, M.; TWARDOWSKI, T. Allelochemical properties of alkaloids effects on plant, bacteria and biosysthesis. In: RIZVI, S. J. H.; RIZVI, V. (Eds.) Allelopathy. New York: Chapmam \& Hall, 1992. p. 129-150. 